\title{
Exploring the Dimensions and Attributes of A Maturity Model for IT Governance Organizational Structures
}

\author{
Dirk Steuperaert \\ University of Antwerp, \\ Antwerp, Belgium \\ Dirk.steuperaert@uantwerpen.be \\ Steven De Haes \\ University of Antwerp, \\ Antwerp, Belgium \\ Steven.dehaes@uantwerpen.be
}

\author{
Tim Huygh \\ Open Universiteit, \\ Heerlen, The Netherlands \\ Tim.huygh@ou.nl \\ Geert Poels \\ Ghent University, \\ Ghent, Belgium \\ Geert.poels@ugent.be
}

\begin{abstract}
Organizations active in today's digitally transforming world require sound IT governance (ITG). Besides processes and relational mechanisms, organizational structures (e.g. IT steering committee) are a key component of ITG. In the context of improving ITG, most of the (limited) existing research however has focused on the process component. The goal of the present research is to determine how ITG structures can be systematically improved. By drawing on the maturity model concept, this paper presents the first version of a maturity model for ITG structures.
\end{abstract}

\section{Introduction}

In today's volatile, uncertain, complex and ambiguous world, organizations are increasingly confronted with digital transformation (i.e. organizational transformation enabled through digital technologies). As a result, organizations are pervasively using digital technologies for supporting, sustaining, and expanding business [1]. To effectively direct and control their digital assets and capabilities, organizations require an appropriate IT governance (ITG) approach [2]. Striving for effective ITG is vital for organizations, as it ultimately enables IT business value, through business/IT alignment [2, 3]. As a result, many organizations are implementing ITG [4].

ITG can be put in place in organizations through implementing a number of (interacting) components. In that context, extant literature has identified a typology of ITG mechanisms; i.e. structures, processes, and relational mechanisms $[3,5,6]$. Besides its implementation, organizations are also concerned with how an existing ITG implementation can be improved [4] (i.e. how it can grow to a desired/adequate maturity level). In this respect, ITG maturity models are useful. However, almost all of the research related to ITG maturity has focused on processes [7]. This also becomes evident from the COBIT framework, which is the leading practitioner framework for IT governance and IT management. Indeed, COBIT has included an approach to gauge the maturity of its processes since the release of COBIT 3 back in 2000 [2]. In the latest edition of the framework (i.e. COBIT 2019), some aspects of performance management of other ITG components (i.e. besides processes) are included. For instance, some criteria are proposed for assessing the performance of ITG structures (e.g. decision rights of the organizational structure are defined and documented) [8]. However, these seemingly haphazard criteria remain rather abstract and unformalized, which is also explicitly acknowledged in the COBIT 2019 documentation: "Although no generally accepted or formal method exists for assessing organizational structures, they can be less formally assessed according to the following criteria [...]" [8]. A survey of the literature on organizational structures in general, and ITG structures in specific, seems to confirm this statement. While some studies (e.g. [9]) propose rather abstract and unsystematic criteria for assessing the performance of organizational structures, equivalent to COBIT 2019, insights on how to systematically improve the performance of organizational structures (i.e. how organizational structures can grow in maturity over distinct maturity stages) seem to be unavailable.

Following this problem statement, the goal of this paper is to determine how ITG structures can systematically be improved. It is the premise of this paper that ITG structures that grow in maturity become more effective, and as such better contribute to IT business value [2]. With the above-mentioned research goal in mind, this paper proposes the first version of a maturity model for ITG structures. This 
maturity model is created based on a literature review and the iterative feedback of a Delphi expert panel. Hence, the following overall research question is put forward to guide this research: How can a maturity model for IT governance structures be created? To better address this overall research question, the following sub questions are identified:

- RQ0: To what extent is the concept of a maturity model relevant for IT governance structures?

- RQ1: What are useful dimensions along which the maturity of IT governance structures can be assessed?

- RQ2: What are useful attributes for each of these dimensions?

- RQ3: How can these attributes be ordered over different maturity stages as part of a maturity model for IT governance structures?

The results of this research add to the body of knowledge by improving our understanding of how the maturity of ITG structures can systematically be improved. By drawing on the concept of a maturity model, the present research introduces a concept originating from quality management in the previously uncharted territory of ITG structures. Furthermore, the results of this study can help organizations that want to improve the maturity of their ITG structures in the context of improving their ITG.

The remainder of this paper is structured as follows. Section 2 outlines the theoretical background, including IT governance in general, IT governance structures in specific, and maturity models. Section 3 describes the research design and approach, while Section 4 reports the study findings. In section 5 , a conclusion to the research is provided. After that, section 6 outlines the implications for theory and practice, and section 7 discusses some limitations and suggestions for future research.

\section{Theoretical background}

\subsection{IT governance and its structures}

The specific term IT governance started to appear in academic outlets in the early 1990s. Early research in this area especially focused on the locus of IT decision-making authority, the structural arrangements to organize this in an organization, and the contingency factors that may influence the choice for a specific structural arrangement [10]. Following a growing interest from practice, later research started to integrate these issues in the form of IT governance frameworks (e.g. [6]) [10].

This evolution was accompanied by a growing interest in the actual mechanisms through which ITG could be implemented in an organization $[3,5,6]$. In that context, scholars quickly came to an agreement regarding the identification of a typology of ITG mechanisms; i.e. structures, processes, and relational mechanisms [2, 3, 5, 6]. Scholars also reached agreement about the outcomes of ITG. The commonly shared viewpoint is that ITG ultimately results in IT business value, through the mediating mechanism of business/IT alignment [2, 3]. Fully in line with the above, IT governance is viewed herein as " $[. .$.$] an$ integral part of corporate governance for which the board is accountable. It involves the definition and implementation of processes, structures and relational mechanisms that enable both business and IT stakeholders to execute their responsibilities in support of business/IT alignment, and the creation and protection of IT business value." [2]

In the context of identifying the actual mechanisms through which ITG can be implemented in an organization, multiple specific organizational structures were proposed (besides processes and relational mechanisms). In general, ITG structures represent organizational units and roles responsible for IT-related decision-making $[3,5,6]$. Some examples of concrete ITG structures that are proposed in extant literature include: (1) An IT steering committee (composed of senior business and IT executives) which focuses on prioritizing IT investments, resource allocation related to IT, and tracking IT projects [11], (2) An IT security steering committee which focuses on IT-related risks and security issues [3], (3) An IT leadership committee (e.g. populated by all divisional CIOs), which has the responsibility of establishing ITrelated standards [6], and (4) A board-level committee chartered with setting direction towards, and being in control of, the organization's IT (e.g. labeled IT oversight committee) [12].

While these insights are useful for organizations that want to implement ITG, a list of concrete ITG structures does not provide insights on how these structures can be improved (i.e. grow to a desired/adequate maturity level). In that regard, maturity models can be useful [7].

\subsection{Maturity models}

The contemporary concept of maturity models has its roots in statistical quality control and quality management. In 1979, Crosby [13] introduced maturity stages in the context of quality management. In general, a maturity model can be used to determine the as-is state, and following an analysis of the gap (if any) between the desired to-be situation and the as-is situation, it can be used to derive improvement 
measures [14]. In the realm of IT, the most wellknown maturity model is the Capability Maturity Model (CMM), developed by the Software Engineering Institute (SEI) [15]. Since its initial release in 1991, its enormous popularity acted as a catalyst for the release of numerous maturity models in different domains [16]. However, CMM-based maturity models are heavily focused on the maturity of processes, while other important aspects of organizations (e.g. organizational culture) are largely neglected in its applications [17]. Indeed, the vast majority of applications of maturity models is oriented at business processes [18].

Unsurprisingly, the same observation applies for ITG. Indeed, based on the results of an extensive literature review, it can be concluded that most of the (limited) existing research regarding ITG maturity has focused on ITG processes [7]. Moreover, while COBIT (i.e. the leading practitioner framework for IT governance and IT management) has included a formal (CMM-based) approach to gauge the maturity of its processes since the release of COBIT 3 back in 2000 [2], it is explicitly acknowledged in COBIT 2019 that "[...] no generally accepted or formal method exists for assessing organizational structures [...]" [8].

The goal of the present research is to determine how ITG structures can be systematically improved (i.e. grow in maturity to a desired/adequate maturity level), by drawing on the maturity model concept. Herein, a maturity model is viewed as "[consisting] of a sequence of maturity levels for a class of objects. It represents an anticipated, desired, or typical evolution path of these objects shaped as discrete stages. " [14]. In referring to objects, this view acknowledges that maturity models can be leveraged outside the realm of processes. In the context of the present research, these objects are ITG structures.

\section{Methodology}

To meet the goal of this research, a Delphi study was conducted. Generally speaking, the Delphi method is aimed at building consensus related to a specific topic of interest, using a structured iterative process of questionnaires [19], while extensively drawing on the knowledge and judgment of a panel of carefully-selected experts [20]. Representing an inductive, data-driven approach, the Delphi method is particularly useful in the context of exploratory research [21]. As we previously established that insights on how to systematically improve the performance of organizational structures seem to be unavailable in extant literature, the Delphi method hence qualifies as an appropriate research method for the present study. Moreover, specific characteristics of the Delphi method favor its use over other research methods. For instance, as opposed to focus group research, the Delphi method minimizes the potential for manipulation and coercion towards adopting a certain viewpoint among participants, due to the fact that the anonymity of the participants of a Delphi panel is ensured by design [22].

To ensure the validity and reliability of the research results, a rigorous application of the Delphi method is required. To facilitate this, the guidelines (i.e. procedures and quality criteria) for rigorous Delphi research by Okoli \& Pawlowski [20] and Paré et al. [19] were followed. These guidelines concern two main areas, i.e. (1) research design, and (2) data collection and analysis.

\subsection{Research design}

While designing a Delphi study, particular attention should be devoted to the selection of experts who will populate the Delphi expert panel. As the validity of the results of a Delphi study greatly depends on the judgments of the experts, using clear and appropriate selection criteria is crucial [19]. For the present study, three groups of relevant experts (with different backgrounds) and related selection criteria were put forward: (1) Academics studying ITG and/or maturity modelling. These topics correspond to the multi-disciplinary nature of our research. Including academics was deemed relevant for ensuring that the research results are adequately based on scientific insights. Academics were required to have at least one peer-reviewed publication on ITG and/or maturity modelling in the past 3 years. (2) IT practitioners at the middle or senior management level, with proven responsibilities and experience in the context of ITG. This expert profile was deemed relevant for ensuring that the research results adequately correspond to the daily reality in these areas of responsibility, and ensuring that the results are pragmatic and useable in practice. (3) Consultants with proven experience in ITG-related matters. Including this expert profile was deemed relevant as consultants have insights gathered across multiple organizations and projects, thereby limiting the chance that the research results are biased towards a certain organization or industry.

Potential panelists were recruited through two main channels, i.e. the network of our university research group, and ISACA (i.e. the organization behind the COBIT framework). In total, 80 potential experts were invited to participate in the Delphi research $(26 \%$ academics, $48 \%$ IT practitioners, and 
$26 \%$ consultants), of which 43 (10 academics, 12 IT practitioners, 18 consultants, and 3 unknown) committed to participate and completed the first questionnaire round, resulting in a response rate of $54 \%$. Of this initial panel, 33 experts indicated that they wanted to participate in the following questionnaire round, of which 25 experts (76\%) effectively completed it. Out of these 25 responses, three were significantly incomplete, resulting in a final panel size of 22 ( 5 academics, 7 IT practitioners, 9 consultants, and 1 unknown). As such, the final round of the Delphi research was completed with a panel size well over the recommended panel size of 18 [20].

\subsection{Data collection and analysis}

Data collection and analysis of the present Delphi study followed a three-phase approach. In the preparatory phase ("phase 0"), a literature review was conducted on performance management methods for organizational structures and the applicability of the maturity model concept in the context of organizational structures in general, and ITG structures in specific. Combinations of organiz(s)ational structure, committee, (IT) governance, performance (management), capability, and maturity were used in WoS to find potentially relevant literature. While a specific maturity model for ITG structures (or by extension for any type of organizational structures) does not appear to exist, some insights however are available on the dimensions and specific attributes that may be used to assess the performance of organizational/ITG structures in the context of a maturity model. As such, this phase also included identifying an initial set of dimensions and attributes for a maturity model for ITG structures based on existing sources.

The next phase ("phase 1"), consisted of the first questionnaire round of the Delphi research. The main goals of this phase were to confirm the relevance of the maturity model concept in the context of ITG structures, and a first evaluation and ranking of the initial set of dimensions and corresponding attributes. First, panelists were asked to indicate the relevance of the maturity model concept in the context of ITG processes $^{1}$ and ITG structures. Second, panelists were

\footnotetext{
${ }^{1}$ Gauging the perceived relevance of a maturity model in the context of ITG processes was deemed relevant to be able to compare these results with the perceived relevance of the concept in the context of ITG structures, given the fact that almost all of the existing applications of maturity models in the context of ITG focus on processes.

${ }^{2}$ The 4-point ordinal scale is: irrelevant - somewhat irrelevant somewhat relevant - highly relevant. Dimensions will be retained if they at least score somewhat relevant on average.
}

asked to rank the proposed dimensions according to their relevance (on a 4-point ordinal scale) $)^{2}$. Finally, panelists were asked to indicate for each of the proposed attributes (within their respective dimensions) whether: it is not a relevant attribute; or it is a minimally required attribute that even the most basic ITG structure should have; or it is an attribute that a somewhat more advanced, normally functioning ITG structure should have; or it is an attribute that only a very advanced, highly performant ITG structure should have ${ }^{3}$. In terms of evaluation, panelists were able (through answering open questions) to provide suggestions for rephrasing, removing existing, or adding new dimensions (and their respective descriptions) and/or attributes. This safeguard is useful to prevent that the research results are biased by (potential limitations of) the literature and to avoid that the study is too much controlled by the researcher(s) [23]. As a result of this, multiple changes were indeed proposed and incorporated to the initial dimensions (i.e. rephrasing of descriptions) and attributes (i.e. rephrasing, splitting existing ones, and adding new ones) in preparation of the next phase of the Delphi research.

The final phase ("phase 2") involved the second questionnaire round of the Delphi research. The main goals of this phase were (1) to gauge the appropriateness of a proposed set of maturity levels for organizational structures, (2) to provide a final ranking of the attributes (within their corresponding dimensions), and (3) to assign these attributes to the proposed maturity levels in the context of a maturity model for ITG structures. First, panelists were provided with a proposed set of distinct maturity levels (and corresponding descriptions) for organizational structures and were asked to evaluate its appropriateness (in terms of: number of levels, names and descriptions). Second, panelists were asked to rank the attributes within their respective dimensions (i.e. 5 rankings had to be provided - one for each dimension) according to the level of sophistication (from most basic to most advanced) of the organizational structure to which the attribute belongs. Third, panelists were asked to assign each attribute to one of the proposed maturity levels (taking into

\footnotetext{
${ }^{3}$ The insights gathered through these questions allowed us to: (1) gauge the relevance of all attributes, and (2) gauge whether, within a given dimension, it was possible to differentiate between basic attributes and more advanced attributes (which is of course an essential requirement to build a maturity model based on these attributes).
} 
account their previous rankings of attributes according to the level of sophistication).

It is common practice to stop the Delphi research (i.e. refrain from conducting further iterations) if certain conditions are met (mostly related to the degree of consensus among the expert panel) [19]. For that reason, after conducting the first iteration of phase 2, it was decided to stop the Delphi research. It appeared that an acceptable level of agreement (for the majority of the 5 dimensions) was obtained among the experts about the ranking of the attributes according to the level of sophistication of the ITG structure to which the attributes belong. To evaluate the degree of consensus among the experts, Kendall's W (i.e. Kendall's coefficient of concordance) was calculated, for each of the dimensions. Commonly accepted rules of thumb for the values of Kendall's W have been proposed. More specifically, $\mathrm{W}>0.7$ indicates strong consensus, $0.5 \leq \mathrm{W} \leq 0.7$ indicates moderate consensus, and $\mathrm{W}<0.5$ indicates weak consensus [24]. Using these rules of thumb, moderate consensus was reached for three out of 5 dimensions, and weak consensus (more specifically $\mathrm{W}=0.4$ ) was reached for the remaining two dimensions. However, the trade-off between feasibility and potential benefits of conducting further iterations is also an important consideration [24]. As indicated by the significant amount of experts dropping out of the study between phase 1 and phase 2 (i.e. the panel size shrunk from 43 to 22), a decrease in the experts' motivation could be observed. This observation, combined with the fact that moderate consensus was already achieved for the majority of dimensions (which is an acceptable stopping criterion [24]), led to the decision to refrain from further straining the expert panel.

\section{Findings}

\subsection{Relevance of the concept of a maturity model for IT governance structures}

The initial literature review (part of "phase 0") indicated that a specific maturity model for organizational structures in general, as well as for ITG structures in specific, did not appear to exist. Specifically in the context of ITG structures, it is furthermore explicitly mentioned in the COBIT 2019 framework that "[...] no generally accepted or formal method exists for assessing organizational structures [...]" [8]. Extant literature however does indicate that maturity models can be useful in the context of improving an ITG implementation [4] (i.e. growing it to a desired/adequate maturity level), and that ITG structures are an essential element of any ITG implementation [3]. For that reason, it is not unreasonable to explore the relevance of the maturity model concept in the context of ITG structures. As such, the Delphi expert panel was first asked to assess the perceived relevance of the maturity model concept in this specific context. The results indicate that, among the Delphi panel, there is a $83 \%$ agreement that the maturity model is a valuable technique to measure the performance of ITG processes, and a 76\% agreement that the maturity model is potentially relevant (and should be explored) in the context of ITG structures. Hence, the expert panel seems to indicate that maturity models may thus not only be relevant in the context of ITG processes.

\subsection{Dimensions and attributes for assessing the maturity of IT governance structures}

Based on the literature review that was conducted in the context of the preparatory phase ("phase 0") of the Delphi research, an initial set of candidate attributes for a maturity model for organizational/ITG structures was identified. Insights from academic literature were combined with relevant insights from the COBIT framework, as the latter source also provides some information related to the performance management of organizational structures.

Although limited, existing research provides some insights concerning the performance management of organizational structures. Prasad et al. [25] used a set of specific measurement items to assess the effectiveness of suggested ITG committees (e.g. cocreated IT steering committee). Sun et al. [9] examined whether the relationship between future firm performance and CEO stock option grants is affected by the quality of the compensation committee. In that regard, a set of specific measurement items was proposed to operationalize 'compensation committee quality'. Finally, Schmidt et al. [26] discuss the challenges of assessing board effectiveness. Key insights include that common output measures (such as meeting frequency and attendance) need to be complemented with process measures that measure consistency between decisions and actual behavior.

Besides academic literature, leading practitioner ITG frameworks and standards were also reviewed. The ISO/IEC 38500:2015 [27] standard does mention some roles and organizational structures that are important in the context of ITG (e.g. CIO, IT steering committee), but insights about the dimensions and specific attributes to assess the performance of ITG structures are lacking. The COBIT [8, 28] framework however does provide such insights. First, several 
candidate attributes are provided in COBIT 2019 that may be used in the context of a maturity model for ITG structures. In addition to these attributes, the COBIT 5 framework (i.e. previous edition) also provides insights that can be useful for grouping specific attributes into dimensions. More specifically, the following generic enabler dimensions are listed therein: stakeholders, goals, lifecycle, and, good practices [28]. Bringing the insights from academic literature together with the insights from COBIT, the stakeholders dimension was renamed to composition \& resources, and the goals dimension to decisionmaking \& responsibilities. These terms better suit the specific context of organizational structures and better align to the insights provided in academic literature. Finally, the dimension communication was added. While COBIT includes communication-related attributes under the general heading of nonfunctional practices [8], academic literature [25] explicitly identifies this as a crucial high-level aspect of effective organizational structures.

Table 1 summarises the results of this literature review. It provides an initial set of dimensions and corresponding specific attributes to be provided to the Delphi expert panel for evaluation, as part of the next phase ("phase 1") of the Delphi research.

Table 1. Initial set of dimensions and attributes

\begin{tabular}{|c|c|c|}
\hline Dimensions & Attributes & Sources \\
\hline \multirow[t]{4}{*}{$\begin{array}{c}\text { Lifecycle } \\
\text { Management }\end{array}$} & $\begin{array}{l}\text { The organizational structure is } \\
\text { formally defined. }\end{array}$ & {$[9],[8]$} \\
\hline & $\begin{array}{l}\text { Performance of the organizational } \\
\text { structure is planned and } \\
\text { monitored. }\end{array}$ & [8] \\
\hline & $\begin{array}{l}\text { Performance of the organizational } \\
\text { structure is adjusted to meet } \\
\text { plans. }\end{array}$ & [8] \\
\hline & $\begin{array}{l}\text { Regular evaluations result in the } \\
\text { required continuous improvement } \\
\text { of the organizational structure (in } \\
\text { its composition, mandate, or any } \\
\text { other parameter). }\end{array}$ & [8] \\
\hline \multirow[t]{5}{*}{$\begin{array}{l}\text { Composition } \\
\& \text { Resources }\end{array}$} & $\begin{array}{l}\text { The organizational structure has a } \\
\text { clear mandate. }\end{array}$ & {$[26],[8]$} \\
\hline & $\begin{array}{l}\text { Defined members of the } \\
\text { organizational structure are } \\
\text { participating and assuming their } \\
\text { roles. }\end{array}$ & $\begin{array}{l}{[25],} \\
{[26]}\end{array}$ \\
\hline & $\begin{array}{l}\text { Resources and information } \\
\text { necessary for the organizational } \\
\text { structure are identified, made } \\
\text { available, allocated and used. }\end{array}$ & [26], [8] \\
\hline & $\begin{array}{l}\text { Members of the organizational } \\
\text { structure have the required skills. }\end{array}$ & [9] \\
\hline & $\begin{array}{l}\text { The members of the } \\
\text { organizational structure are } \\
\text { defined. }\end{array}$ & $\begin{array}{l}{[25],} \\
{[26]}\end{array}$ \\
\hline $\begin{array}{c}\text { Good } \\
\text { Practices }\end{array}$ & $\begin{array}{l}\text { Escalation procedures are } \\
\text { defined. }\end{array}$ & [8] \\
\hline
\end{tabular}

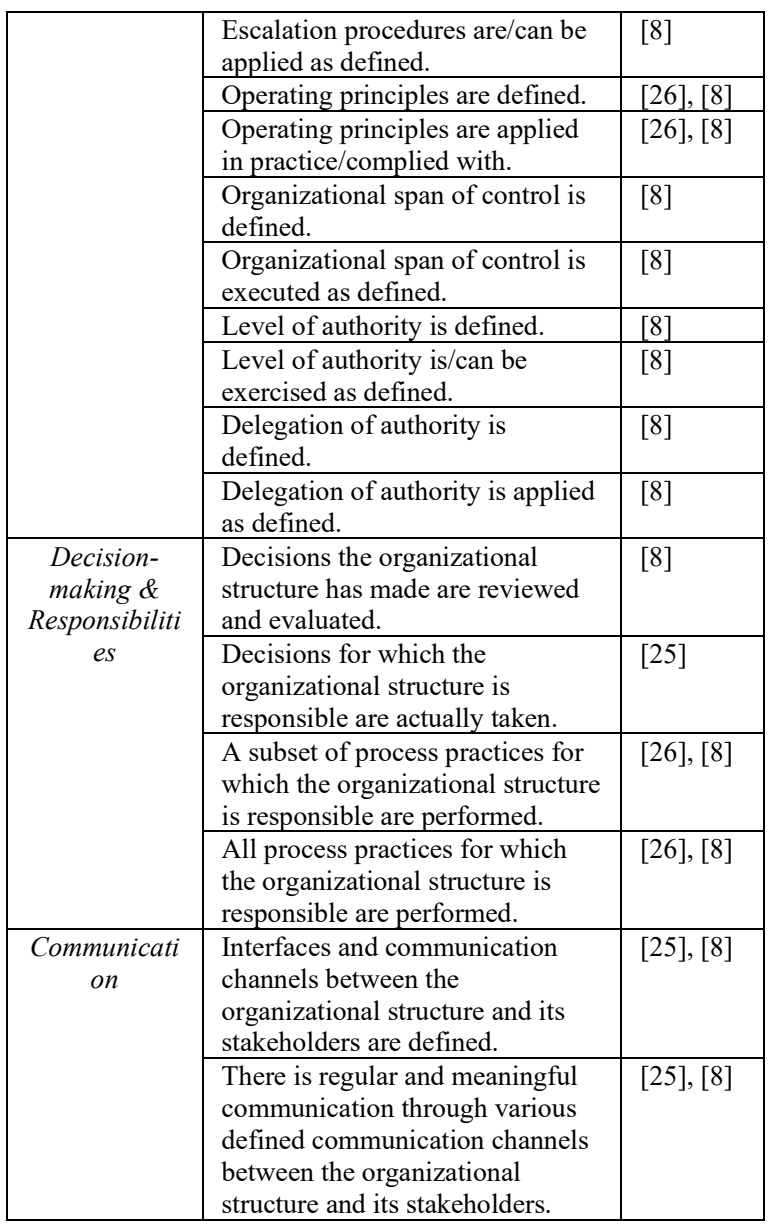

The results of this evaluation indicate that the proposed dimensions can be considered as validated by the panel (see Figure 1), as all 5 dimensions score at least somewhat relevant on average.

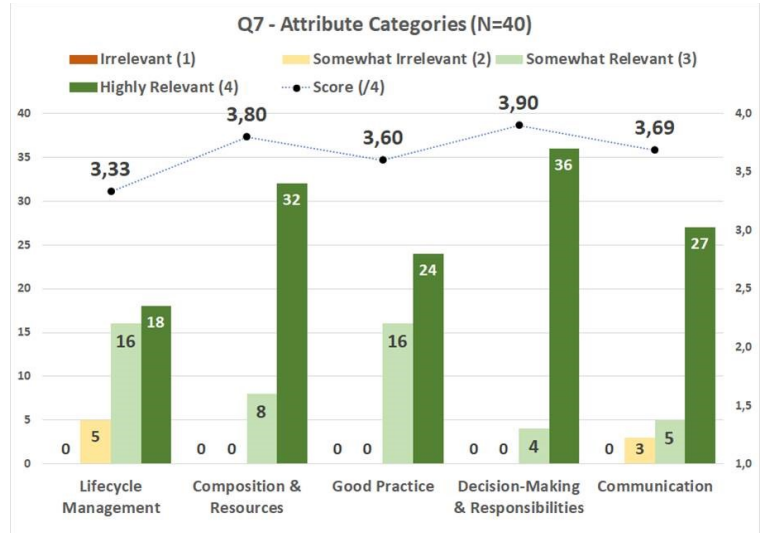

Figure 1. Perceived relevance of dimensions

However, the Delphi panel made some suggestions for improvement, which resulted in rephrasing the description of certain dimensions. No open-ended 
feedback was received however that would require the removal of initial dimensions and/or the introduction of new ones. As a result, the following 5 dimensions (and corresponding descriptions) are the output of this research step (see Table 2).

Table 2. Validated dimensions and descriptions

\begin{tabular}{|l|l|}
\hline \multicolumn{1}{|c|}{ Dimensions } & \multicolumn{1}{|c|}{ Descriptions } \\
\hline $\begin{array}{l}\text { Lifecycle } \\
\text { management }\end{array}$ & $\begin{array}{l}\text { An organizational structure has to be set- } \\
\text { up, and its performance needs to be } \\
\text { managed throughout its useful existence. }\end{array}$ \\
\hline $\begin{array}{l}\text { Composition \& } \\
\text { resources }\end{array}$ & $\begin{array}{l}\text { An organizational structure requires } \\
\text { members with certain skill sets and the } \\
\text { necessary resources to operate. }\end{array}$ \\
\hline Good practices & $\begin{array}{l}\text { An organizational structure requires a } \\
\text { number of good practices to be complied } \\
\text { with (e.g. operating principles, level of } \\
\text { authority, span of control, etc.) }\end{array}$ \\
\hline $\begin{array}{l}\text { Decision- } \\
\text { making \& } \\
\text { responsibilities }\end{array}$ & $\begin{array}{l}\text { The organizational structure is making } \\
\text { decisions as per their mandate and level of } \\
\text { authority and executes the tasks they are } \\
\text { responsible for. }\end{array}$ \\
\hline Communication & $\begin{array}{l}\text { The organizational structure communicates } \\
\text { effectively with its stakeholders. }\end{array}$ \\
\hline
\end{tabular}

The next part of the first round questionnaire dealt with the initial list of specific attributes, and was aimed at gathering insights that would allow: (1) gauging the relevance of each attribute, and (2) gauging whether, within a given dimension, it was possible to differentiate between basic attributes and more advanced attributes. The latter is of course a crucial requirement to be able to use the attributes in the context of a maturity model with distinct maturity levels.

Upon analysing the results, no attribute received more than 3 not relevant ratings (out of 43 completed questionnaires), which clearly indicates that all the specific attributes are considered relevant by the expert panel. Moreover, enough differentiation ${ }^{4}$ was observed between more basic and more advanced attributes, which provides confidence that the attributes can be mapped to distinct maturity levels (in the following phase of the Delphi research). It is important to note that this step was included simply as an exploratory check in the context of the initial list of attributes. Indeed, the initial list of attributes could still change after this phase (based on the open-ended feedback of the expert panel), and therefore the actual mapping of attributes to maturity levels will be initiated in "phase 2" of the Delphi research (after the introduction of the actual maturity levels).

Overall, the results of the first phase of the Delphi research indicate that the initial list of dimensions and

\footnotetext{
${ }^{4}$ On our ordinal scale from 1 to 3 , the average scores of all attributes vary between 1,48 and 2,56. Due to the page restriction, the results of the individual attributes are not provided herein.
}

specific attributes was considered highly relevant by the expert panel. However, some changes to this initial list were proposed through open-ended feedback. This resulted in the incorporation of changes to the initial dimensions (i.e. rephrasing some descriptions) and attributes (i.e. rephrasing, splitting existing ones, and adding new ones) in preparation of the next phase of the Delphi research.

In the second round questionnaire ("phase 2"), the expert panel was asked to rank the updated list of attributes (within their respective dimensions) according to the level of sophistication (from most basic to most advanced) of the organizational structure to which the attribute belongs ${ }^{5}$. This intermediate step of asking each expert to carefully consider the relative position of each attribute to all other attributes within a given dimension was an important preparation for the final research step, i.e. mapping each attribute to one of the maturity levels. Furthermore, it allowed the calculation of Kendall's W as an indicator for the consensus among the experts. As its values were good for the majority of dimensions, we refrained from conducting further iterations of the final round of the Delphi research (as explained in detail in the methodology section of this paper).

\subsection{Mapping attributes to maturity levels}

Prevailing maturity models (e.g. CMMI) distinguish maturity levels between 0 or 1 to 5 . While it would seem consistent to define a similar number of levels, one could argue for limiting the number of levels in the context of organizational/ITG structures. The main argument here would be that level 5 (e.g. optimizing) is typically associated with frequent monitoring of relevant indicators and continuously adjusting performance based on (statistical) analysis of those indicators. This level thus suits objects that generate lots of performance data and can be swiftly adjusted, like software development processes. A typical organizational structure however, will not generate such data and will not require continuous improvement. Hence, the decision was made to base ourselves on the maturity model that is used in COBIT 2019 for ITG processes (which is CMM-based), but drop level 5. As such, 4 (initial) maturity levels were proposed and provided to the Delphi expert panel for evaluation.

The results of this evaluation indicate that $40 \%$ of the experts find that some changes may be necessary to the descriptions of the maturity levels. Interestingly,

\footnotetext{
${ }^{5}$ Due to the page restriction, the results of this intermediate research step are not presented herein. The list of attributes and their average ranks, within their respective dimensions, is available upon request.
} 
$24 \%$ of the experts argued for including a level 5 , in line with the well-known CMM-based maturity model for processes. However, as more than $75 \%$ of the experts agree with the proposed number of maturity levels, we consider this as validated by the panel. Nevertheless, some final changes were made to the descriptions, based on the open-ended feedback of the expert panel. As a result, the following 4 maturity levels, and corresponding descriptions, are the output of this research step (see Table 3).

Table 3. Maturity levels for ITG structures

\begin{tabular}{|c|l|}
\hline $\begin{array}{c}\text { Maturity } \\
\text { Level }\end{array}$ & \multicolumn{1}{c|}{ Description } \\
\hline 1: Initial & $\begin{array}{l}\text { The organizational structure exists and } \\
\text { demonstrates only the most essential } \\
\text { attributes. }\end{array}$ \\
\hline $\begin{array}{c}\text { Established } \\
\text { Performing }\end{array}$ & $\begin{array}{l}\text { The organizational structure exists and } \\
\text { demonstrates all essential and important } \\
\text { attributes. }\end{array}$ \\
\hline 4: Measured & $\begin{array}{l}\text { The organizational structure is well } \\
\text { established and demonstrates consistent } \\
\text { application of more advanced attributes. }\end{array}$ \\
\hline $\begin{array}{l}\text { The performance of the organizational } \\
\text { structure is measured, and adjustments are } \\
\text { made if necessary. }\end{array}$ \\
\hline
\end{tabular}

A final goal of the second (and final) phase of the Delphi research was to map the attributes to the maturity levels. To guide this, an initial mapping of each attribute to a maturity level was provided, based on the results of the first phase ${ }^{6}$. The experts were asked to confirm this mapping, or to map the attribute to a different maturity level. The results indicate that the expert panel confirms the mapping to a large extent, with a few attributes being transferred to a higher maturity level. The correlation between this mapping and the ranking of attributes within each dimension was also calculated. Correlations between average rank and average maturity level within each dimension are strong (i.e. between 0.74 and 0.99 , with an average of 0.86), which is a clear sign of consistency. As a result, the output of this research consists of a validated list of dimensions, specific attributes, and maturity levels, as well as a mapping of the attributes to the maturity levels. In other words, it consists of a maturity model for ITG structures.

\section{Conclusion}

The problem statement underlying this research was that insights on how to systematically improve the performance of organizational structures (i.e. how

\footnotetext{
6 Attributes that were rated as a minimally required attribute that even the most basic ITG structure should have were initially mapped to level 1; attributes that were rated as an attribute that a somewhat more advanced, normally functioning ITG structure should have
}

organizational structures can grow in maturity over different maturity stages) seem to be unavailable in extant literature. Following that, the goal of this research was to determine how ITG structures can systematically be improved. With that goal in mind, this paper proposed the first edition of a maturity model for ITG structures, through answering the overall research question "How can a maturity model for IT governance structures be created?"

Through an initial literature review and two rounds of Delphi research, the following main conclusions were drawn. First, the maturity model concept is considered relevant in the context of ITG structures. This is interesting, as most of the (limited) existing research related to ITG maturity has focused on ITG processes. Second, a set of specific attributes (grouped into 5 dimensions) was identified, evaluated and validated. These attributes can: (1) be used to describe various aspects of the performance of ITG structures, and (2) be mapped to distinct, increasing levels of maturity. In summary, the present research did output a set of specific attributes (grouped into different dimensions) and maturity levels as a validated basis for a maturity model for ITG structures.

The conclusion of the present research can as such be summarized in the following proposed maturity model for ITG structures (version 1.0), which distinguishes 4 maturity levels and 33 attributes grouped into 5 dimensions (see Table 4). The dimensions are coded as follows: $\mathrm{LM}=$ Lifecycle Management, $\mathrm{CR}=$ Composition \& Resources, $\mathrm{GP}=$ Good Practices, $\mathrm{DR}=$ Decision-making \& Responsibilities, $\mathrm{CO}=$ Communication.

\section{Table 4. Maturity model for IT governance} structures

\begin{tabular}{l} 
Maturity level 1: Initial \\
\hline [DR] A subset of the most essential process practices for which \\
the organizational structure is responsible are performed. \\
\hline$[\mathrm{CR}]$ The members of the organizational structure are defined. \\
\hline$[\mathrm{CR}]$ The organizational structure has a clear mandate. \\
\hline [CR] Members of the organizational structures are participating \\
in the required activities and decision-making. \\
\hline [LM] The organizational structure is formally defined by the \\
Board or Senior Management. \\
\hline$[\mathrm{GP}]$ Level of authority of the organizational structure is defined. \\
\hline [GP] Delegation of authority of the organizational structure is \\
defined. \\
\hline $\begin{array}{l}\text { [GP] Operating principles for the organizational structure are } \\
\text { defined. }\end{array}$ \\
\hline
\end{tabular}

were evenly distributed between levels 2 and 3; and attributes that were rated as an attribute that only a very advanced, highly performant ITG structure should have were mapped to level 4. 
[CO] Interfaces and communication channels between the organizational structure and its stakeholders are defined and planned.

[CR] Resources necessary for the organizational structure are identified, made available, allocated and used.

[GP] Level of authority of the organizational structure is/can be exercised as defined.

[GP] Escalation procedures for the organizational structure are defined.

[CR] The organizational structure membership is representative for all stakeholders, e.g. contains both IT and business members.

[GP] Organizational span of control of the organizational structure is defined.

[GP] Delegation of authority of the organizational structure is applied as defined.

[DR] All members of the organizational structure stand behind their decisions once they are taken.

[GP] Operating principles of the organizational structure are applied in practice/complied with.

[DR] Decisions for which the organizational structure is responsible are taken swiftly without any undue delay.

[CR] Members of the organizational structures have the required combined skills - including include the subject matter expertise and business awareness - to take appropriate decisions and fulfill their tasks.

[LM] Performance of the organizational structure is planned and monitored by the board or senior management. Maturity level 3: Performing

[CO] Decisions of the organizational structure demonstrate an appropriate amount of risk taking to balance risk and benefits.

[CR] Information necessary for the organizational structure is identified, readily available with the required quality and used appropriately.

[CO] Informal communication channels between the organizational structure and its stakeholders are maintained and used appropriately.

[GP] Escalation procedures for the organizational structure are/can be applied as defined.

[CO] There is regular and timely communication through various defined communication channels between the organizational structure and its stakeholders.

[CR] The organizational structure membership includes appropriate levels of expertise from within the organization. Maturity level 4: Measured

[CO] All members of the organizational structure support the implementation of their decisions once they are taken.

[LM] Performance of the organizational structure is adjusted to meet target performance.

[CO] There is meaningful bi-directional communication through various appropriate communication channels between the organizational structure and its stakeholders.

[GP] Organizational span of control is executed as it was defined.

[DR] All process practices for which the organizational structure is responsible are performed.

[LM] Regular evaluations result in the required continuous improvement of the organizational structure (in its composition, mandate or any other parameter).

[DR] Decisions the organizational structure has taken are reviewed and evaluated by the board or senior management or by an independent reviewer.

\section{Implications for theory and practice}

For academics, this research contributes to the body of knowledge by improving our understanding of how the maturity of ITG structures can systematically be improved (by drawing on the maturity model concept). While most of the (limited) existing research on ITG maturity has focused on ITG processes, this paper explicitly focused on ITG structures. Despite this specific focus, the results of this study may also be applicable, at least to some extent, to other types of organizational structures (however, this requires further research). For practice, the results of this study can help organizations that want to improve the maturity of their ITG structures in the context of an overall ITG improvement. A maturity model-based approach can be useful in that context, as it allows determining an organization's as-is state, and following an analysis of the gap (if any) between the desired to-be situation and the as-is situation, specific improvement measures can be derived.

\section{Limitations and future research}

Before introducing suggestions for future research, we first acknowledge the limitations of the present research. The main limitation relates to the fact that our results are based on a limited number of experts (i.e. 22 in the final phase of the Delphi research). Albeit that the sample in the context of Delphi research is not required to be statistically representative [20], one should still proceed with caution in trying to generalize the results. Nevertheless, it is important to mention that the expert panel was carefully populated, using clear and appropriate selection criteria, and with the goal of covering a broad range of relevant expertise.

Building on the initial insights of the present research, further research is possible and recommended in the following areas. First, the maturity model for ITG structures that was presented herein can now be used in practice (e.g. in the context of case study research). The insights that come out of this can be used to further enrich/refine the first version of this maturity model. Second, maturity models can be used for benchmarking (i.e. comparing the results of maturity assessments across organizations or industries). Using our maturity model, this could result in potentially interesting insights on the state of the maturity of ITG structures (e.g. in different industries). Third, there is considerable debate concerning the question whether higher maturity levels are better than lower maturity levels. It might indeed be the case that, once a certain maturity level is achieved, an even higher maturity level (if any) is not better or more desirable for a specific organization. This warrants further investigation in the context of ITG structures. Finally, future research might investigate to what extent the 
present maturity model is applicable in the context of other types of organizational structures (e.g. corporate governance).

\section{References}

[1] J. B. Price and N. Lankton, "A Framework and Guidelines for Assessing and Developing BoardLevel Information Technology Committee Charters," Journal of Information Systems, vol. 32, no. 1, pp. 109-129, 2018.

[2] S. De Haes, W. Van Grembergen, A. Joshi, and T. Huygh, Enterprise Governance of Information Technology: Achieving Alignment and Value in Digital Organizations, Third Edition. Cham, Switzerland: Springer, 2020.

[3] S. De Haes and W. Van Grembergen, "An Exploratory Study into IT Governance Implementations and its Impact on Business/IT Alignment," Information Systems Management, vol. 26, no. 2, pp. 123-137, 2009.

[4] S. De Haes, T. Huygh, A. Joshi, and W. Van Grembergen, "Adoption and Impact of IT Governance and Management Practices: A COBIT 5 Perspective," International Journal of IT/Business Alignment and Governance (IJITBAG), vol. 7, no. 1, pp. 50-72, 2016.

[5] R. Peterson, "Crafting information technology governance," Information systems management, vol. 21 , no. 4, pp. 7-22, 2004

[6] P. Weill and J. W. Ross, IT Governance: How Top Performers Manage IT Decision Rights for Superior Results. Boston, Massachusetts: Harvard Business School Press, 2004.

[7] D. Smits and J. van Hillegersberg, "Diminishing the Gap Between IT Governance Maturity Theory and Practice: Renewing the Approach," International Journal of IT/Business Alignment and Governance (IJITBAG), vol. 10, no. 1, pp. 121, 2019.

[8] ISACA, "COBIT 2019: Introduction and Methodology," 2018.

[9] J. Sun, S. F. Cahan, and D. Emanuel, "Compensation committee governance quality, chief executive officer stock option grants, and future firm performance," Journal of Banking \& Finance, vol. 33, no. 8, pp. 1507-1519, 2009.

[10] A. Brown and G. Grant, "Framing the frameworks: A review of IT governance research," Communications of the Association for Information Systems, vol. 15, no. 1, pp. 696-712, 2005.

[11] ITGI, "Board Briefing on IT Governance, 2nd Edition," 2003.

[12] R. Nolan and F. W. McFarlan, "Information technology and the board of directors," Harvard business review, vol. 83, no. 10, pp. 1-10, 2005.

[13] P. B. Crosby, Quality is free: The art of making quality certain. New York: McGraw-Hill, 1979.

[14] J. Becker, R. Knackstedt, and J. Pöppelbuß, "Developing maturity models for IT management," Business \& Information Systems Engineering, vol. 1, no. 3, pp. 213-222, 2009.

[15] M. C. Paulk et al., "Capability maturity model for software, version 1.0," 1991.

[16] T. De Bruin, M. Rosemann, R. Freeze, and U. Kaulkarni, "Understanding the main phases of developing a maturity assessment model," in Australasian Conference on Information Systems (ACIS) 2005, 2005.

[17] O. Ngwenyama and P. A. Nielsen, "Competing values in software process improvement: an assumption analysis of CMM from an organizational culture perspective," IEEE Transactions on Engineering Management, vol. 50, no. 1, pp. 100-112, 2003.

[18] A. Tarhan, O. Turetken, and H. A. Reijers, "Business process maturity models: A systematic literature review," Information and Software Technology, vol. 75, pp. 122-134, 2016.

[19] G. Pare, A.-F. Cameron, P. Poba-Nzaou, and M. Templier, "A systematic assessment of rigor in information systems ranking-type Delphi studies," Information \& management, vol. 50, no. 5, pp. 207-217, 2013

[20] C. Okoli and S. D. Pawlowski, "The Delphi method as a research tool: an example, design considerations and applications," Information \& management, vol. 42, no. 1, pp. 15-29, 2004.

[21] U. G. Gupta and R. E. Clarke, "Theory and applications of the Delphi technique: A bibliography (1975-1994)," Technological forecasting and social change, vol. 53, no. 2, pp. 185-211, 1996.

[22] N. Dalkey and O. Helmer, "An experimental application of the Delphi method to the use of experts," Management science, vol. 9, no. 3, pp. 458-467, 1963

[23] J. R. Avella, "Delphi panels: Research design, procedures, advantages, and challenges," International Journal of Doctoral Studies, vol. 11, no. 1, pp. 305-321, 2016.

[24] R. C. Schmidt, "Managing Delphi surveys using nonparametric statistical techniques," decision Sciences, vol. 28, no. 3, pp. 763-774, 1997.

[25] A. Prasad, P. Green, and J. Heales, "On IT governance structures and their effectiveness in collaborative organizational structures," International Journal of Accounting Information Systems, vol. 13, no. 3, pp. 199-220, 2012.

[26] S. L. Schmidt and M. Brauer, "Strategic governance: How to assess board effectiveness in guiding strategy execution," Corporate Governance: An International Review, vol. 14, no. 1, pp. 13-22, 2006.

[27] ISO/IEC Standard 38500:2015, ISO/IEC, 2015.

[28] ISACA, "COBIT 5: A Business Framework for the Governance and Management of Enterprise IT," 2012. 